\title{
Concepções prévias de universitários sobre o sistema imunológico
}

Claudia Marcia Borges Barreto

Gerlinde Agate Platais Brasil Teixeira

\section{Resumo}

A teoria da aprendizagem significativa reforça a necessidade de se estabelecer a interação, não arbitrária e não literal, entre materiais, mecanismo de aprendizagem, informação nova e os conhecimentos prévios do estudante. Assim, os objetivos do trabalho são conhecer, avaliar e discutir as concepções prévias que alunos universitários, de primeiro ano da área da ciência da vida, apresentam sobre o sistema imunológico. Esperamos, com esta pesquisa exploratória, contribuir para a reflexão crítica sobre a importância da base teórico-pedagógica empregada na construção ativa dos conceitos científicos. Os resultados revelaram que uma minoria dos participantes apresentou conceitos adequados sobre os componentes do Sistema Imunológico. Concluímos que a maioria dos participantes completou o ensino médio sem os conhecimentos básicos de Imunologia, apresentando pseudoconceitos que permitem a comunicação, mas que podem interferir na aquisição e compreensão de novos conhecimentos científicos.

Palavras-chave: sistema imunológico, teoria sociocultural, livro texto, aprendizagem significativa, conceito.

\begin{abstract}
Meaningful learning theory stress the need to establish non arbitrary and non literal relations between materials, learning mechanism, new information and prior knowledge of the student. Thus, the goals of this paper are to know, evaluate and discuss the prior concepts that first year life science college students present on the immunological system. We expect, that this exploratory research, will contribute with a critical reflection on the importance of the theoretical basis used during teaching to promote active construction of scientific concepts. Our results revealed that a minority of students present appropriate concepts for the components of the immunological system. In conclusion we can say that the majority of the participants of this study completed high school without the basic knowledge of Immunology. They present pseudoconcepts that enable communication, but that can interfere with the acquisition of new scientific knowledge.
\end{abstract}

Keywords: Young immunological system, textbook, previous knowledge, meaningful learning. 


\section{Introdução}

Existem duas teorias de aprendizagem que são complementares e indispensáveis ao processo de aquisição de conceitos científicos. A teoria sociocultural de Vigotski e a aprendizagem significativa de Ausubel. Segundo Vigotski (2008), a formação de conceitos envolve fatores como o desenvolvimento das funções psicológicas superiores, a cultura, os estímulos do meio e o uso das palavras ou outros signos representacionais do pensamento. Aprender a direcionar os próprios processos mentais com a ajuda das palavras é uma parte do processo da formação de conceitos.

O desejo de aprender e a necessidade da informação nova fazer sentido e se relacionar com os conhecimentos prévios do aprendiz são duas premissas importantes para a aprendizagem significativa (Ausubel, 1980). A revisão desta teoria trinta anos mais tarde, intitulada assimilação da aprendizagem e da retenção significativas, reforça a necessidade da interação, não arbitrária e não literal, entre - materiais, mecanismo de aprendizagem, informação nova e os conhecimentos prévios do aprendiz (Ausubel, 2003). Estudos relativos à aprendizagem significativa (Driver, 1986; Driver, 1988) e sociocultural (Mortimer, 2002), consideram os conhecimentos prévios e a participação ativa dos estudantes como elementos chave na construção de significados.

A pesquisa sobre a mudança conceitual no ensino de ciências originou-se dos estudos sobre os conceitos espontâneos (ingênuos) dos estudantes em relação aos científicos, realizados preponderantemente na Física (Driver, 1986) e Química (Mortimer, 2002) a partir da década de 70. Como consequência surge o Movimento das Concepções Alternativas (Alternative Concepts Movement), caracterizado por extensa crítica aos trabalhos de Piaget, que davam grande importância ao desenvolvimento de estruturas lógicas necessárias à aprendizagem, desconsiderando na aprendizagem a influência das concepções dos alunos (Mortimer, 1995).

Para planejar estratégias didáticas adequadas ao aprendizado significativo, à construção e à mudança conceitual é necessário trocar o foco da aprendizagem centrada exclusivamente no conteúdo para a aprendizagem centrada no aluno (DiCarlo, 2006). Assim, é imprescindível conhecer as concepções prévias que os alunos trazem dos níveis anteriores da educação formal, não formal e informal.

Durante a educação formal o conteúdo de Imunologia é tradicionalmente apresentado diversas vezes ao longo do Ensino Básico associado ao sistema circulatório. Com o Programa Nacional do Livro Didático, embora tímida, tem havido uma melhoria na apresentação do sistema imunológico. Entretanto, o tema central, que tem sido desenvolvido parcialmente, envolve a vacina e como ela induz a defesa do organismo.

Se por um lado acreditamos que a quantidade de informação sobre o sistema imunológico seja insuficiente, por outro a sua representação imagética inadequada dificulta ainda mais a compreensão da sua organização morfofisiológica. Nas ciências naturais, é frequente o uso de 
imagens na forma de gráficos, esquemas, fotografias, microfotografias, simulações, modelos entre outros como substitutos para a linguagem verbal na descrição de estruturas e mecanismos estudados. No entanto, quando estas não são adequadas como, por exemplo, em esquemas que não respeitam a escala entre as estruturas, pode ocorrer uma sobrecarga cognitiva dos estudantes (Matos, 2010). Um exemplo frequente no ensino de Imunologia é a representação equivocada de receptores nas superfícies celulares. Os receptores (que medem nanômetros) são representados na mesma ordem de grandeza das células (que medem micrometros) quando deveriam ter três ordens de grandeza menores. Entendemos que em esquemas são necessárias certas distorções para a exemplificação, no entanto estas precisam ser esclarecidas aos leitores. Este tipo de equívoco está presente não só nos livros didáticos do ensino básico como também nos livros texto utilizados no ensino universitário.

Até o momento não identificamos na literatura trabalhos relacionados ao levantamento de pré-concepções referentes ao Sistema Imunológico, adquiridos durante a formação de estudantes brasileiros. Portanto, os objetivos do presente trabalho são conhecer, avaliar e discutir as concepções prévias dos universitários sobre o sistema imunológico. Desta forma esperamos contribuir para a reflexão crítica sobre a importância da construção dos conceitos científicos e a base teórico-pedagógica empregada no ensino da Imunologia.

\section{Desenvolvimento}

Essa é uma pesquisa exploratória que contou com a participação de estudantes de cinco cursos de graduação da área de ciências da vida, a saber: Medicina, Biomedicina, Ciências Biológicas, Enfermagem e Odontologia. Foi utilizada uma amostra por conveniência (aquela mais acessível aos professores pesquisadores) composta por estudantes matriculados na disciplina Imunologia, em um período letivo de uma Universidade Federal. O projeto que contempla esta e outras pesquisas foi aprovado pelo Comitê de Ética sob o registro CAAE - 0098.0.258.000-09.

\section{Levantamento de concepções prévias}

Os conhecimentos prévios, relacionados à Imunologia, adquiridos durante a formação dos estudantes no ensino básico, foi avaliado através de um questionário (pré-teste) elaborado com questões abertas. Para a formulação das questões levamos em consideração conceitos básicos que os estudantes deveriam saber para compreender: 1) os fundamentos de práticas imunológicas aplicadas em diferentes contextos de promoção da saúde como, por exemplo, a vacinação e o transplante, 2) o funcionamento do corpo humano, no que se refere ao sistema imunológico, e 3) suas manifestações frente ao meio, imunidade e hipersensibilidade. 
Os questionários foram aplicados aos estudantes antes de cursarem a disciplina Imunologia, isto é, no primeiro dia letivo dos diferentes cursos de graduação. Os estudantes responderam ao questionário, cientes de que não haveria julgamento de valor, com atribuição de notas. Foram informados que suas respostas seriam usadas para avaliar seus conhecimentos prévios sobre Imunologia e para nortear o trabalho do professor em seu planejamento pedagógico, com vistas à eficácia do processo de ensino e aprendizagem.

A análise e avaliação das respostas dadas ao questionário pelos estudantes foram comparadas ao nosso gabarito de respostas (Quadro 1), elaborado a partir de nosso próprio conhecimento científico e com aqueles veiculados nos livros textos de Imunologia, originais e traduzidos, adotados ou não no ensino superior. Esclarecemos que não foi possível usarmos apenas as informações contidas nos livros texto por não concordarmos conceitualmente com os autores. A título de exemplo, usamos a palavra imunológico ao invés de imune, frequentemente empregada por diferentes autores, para nos referirmos ao sistema em estudo. Por outro lado, concordamos com o dicionário Houaiss (2001) que apresenta o significado para a primeira palavra como referente à imunologia e a última como algo que é dotado de imunidade.

\begin{tabular}{|c|c|}
\hline \multicolumn{2}{|c|}{ GABARITO } \\
\hline Questões & Respostas/Conceitos \\
\hline Qual é a função do sistema imunológico? & $\begin{array}{l}\text { Proteção do organismo contra agentes agressores, } \\
\text { mantendo a homeostasia. } \\
\text { Obs: Optamos por esse conceito por ser o mais } \\
\text { comum entre autores e docentes. }\end{array}$ \\
\hline Como o sistema imunológico é classificado? & Sistema imunológico inato e adaptativo \\
\hline $\begin{array}{l}\text { Esquematize a organização dos componentes do } \\
\text { sistema imunológico de um mamífero. }\end{array}$ & $\begin{array}{l}\text { Foram considerados esquemas, desenhos ou } \\
\text { sequências que revelassem o modelo de sistema } \\
\text { imunológico dos estudantes, com base nas } \\
\text { seguintes informações: órgãos linfoides primários e } \\
\text { secundários, tecidos linfoides e células do sistema } \\
\text { inato e adaptativo. }\end{array}$ \\
\hline Conceitue antígeno. & $\begin{array}{c}\text { Moléculas que interagem com receptores clonais de } \\
\text { linfócitos B ou T capaz de induzir a ativação dessas } \\
\text { células. }\end{array}$ \\
\hline Conceitue anticorpo. & $\begin{array}{l}\text { Glicoproteínas, sintetizadas e secretadas por } \\
\text { linfócitos B, que ao interagir especificamente com }\end{array}$ \\
\hline
\end{tabular}




\begin{tabular}{|c|c|}
\hline $\begin{array}{l}\text { Conceitue vacina. } \\
\text { antígenos podem desencadear processos biológicos. }\end{array}$ & $\begin{array}{r}\text { Produtos derivados de agentes infecciosos } \\
\text { administrados em hospedeiros para induzir } \\
\text { imunidade específica. }\end{array}$ \\
\hline Conceitue imunidade humoral. & $\begin{array}{c}\text { Estado de resistência específica à agentes } \\
\text { infecciosos mediado por anticorpos. }\end{array}$ \\
\hline Conceitue imunidade celular. & $\begin{array}{c}\text { Estado de resistência específica à agentes } \\
\text { infecciosos mediado por células. }\end{array}$ \\
\hline Conceitue memória imunológica. & $\begin{array}{c}\text { Fenômeno do sistema imunológico caracterizado } \\
\text { pela rapidez e intensidade da resposta imunológica } \\
\text { a contatos subsequentes com um determinado }\end{array}$ \\
\hline Conceitue rejeição imunológica. & $\begin{array}{r}\text { Destruição de células, tecidos ou órgãos enxertados } \\
\text { por reações imunológicas. }\end{array}$ \\
\hline
\end{tabular}

Quadro 1 Gabarito usado para a avaliação das respostas dadas às questões abertas do questionário

- As respostas dos estudantes foram classificadas em:

- Adequadas - conceitos semelhantes àqueles do gabarito;

- Inadequadas - conceitos incompletos ou formulados com uso de termos ultrapassados;

- Erradas - nenhuma das situações anteriores;

- Ausentes - não respondidas pelos estudantes.

- Para fins de comparação e discussão dos resultados, também foram analisados, quanto ao conteúdo relacionado à Imunologia, três livros didáticos do ensino fundamental e três do ensino médio de ciências e biologia respectivamente. São livros do professor comumente adotados, sendo um deles aprovado pelo Programa Nacional do Livro Didático (PNLD). Os livros texto de Imunologia, adotados no ensino superior, são de autores reconhecidos internacionalmente. Os livros analisados estão relacionados abaixo:

- "Imunologia celular e molecular" Abbas and Lichtman, 2005;

- "Imunologia Básica" (Abbas and Lichtman, 2007);

- "Imunobiologia" (Janeway et al., 2002);

- "Biologia em foco" (Carvalho, W, 2002, Livro do professor); 
- "Biologia - série novo ensino médio" (Paulino, WR, 2002, Livro do professor);

- "Biologia" (Lopes, S e Rosso, S, 2009, Livro do professor); aprovado pelo Programa Nacional do Livro Didático (PNLD);

- "Ciências: corpo humano" (Fonseca, A, Coleção Horizontes, IBEP, Livro do professor sem data);

- "O Corpo Humano" (Barros \& Paulino, 2001)

- "Ciência \& Sociedade: a aventura do corpo, a aventura da vida, a aventura da tecnologia" (Bertoldi \& De Vasconcellos, 2000).

\section{Resultados}

\section{Avaliação das Concepções dos Estudantes}

O questionário foi aplicado a um total de 140 estudantes, de um universo de 180, vinculados aos cursos de Medicina (61 alunos), Biomedicina (6 alunos), Ciências Biológicas (27 alunos), Farmácia (36 alunos) e Odontologia (10 alunos).

Cada resposta foi avaliada através da identificação da ideia ou do conceito central e em seguida classificada em adequada, inadequada, errada ou ausente, de acordo com o nosso gabarito (Quadro 1). Uma síntese dos resultados quantificados, relativos a cada questão, encontra-se na Tabela 1. Nas descrições dos resultados, apresentamos os exemplos de respostas efetuadas pelos estudantes, a fim de ressaltar as concepções alternativas ou equivocadas.

\begin{tabular}{|c|c|c|c|c|}
\hline Questões & Adequadas & Inadequadas & Erradas & Ausentes \\
\hline $\begin{array}{c}\text { Qual é a função do sistema } \\
\text { imunológico? }\end{array}$ & $52,0 \%$ & $46,6 \%$ & $1,4 \%$ & 0 \\
\hline $\begin{array}{c}\text { Como o sistema imunológico é } \\
\text { classificado? }\end{array}$ & $12,0 \%$ & $3,0 \%$ & $38,5 \%$ & $46,5 \%$ \\
\hline $\begin{array}{c}\text { Esquematize a organização dos } \\
\text { componentes do sistema imunológico }\end{array}$ & $0,7 \%$ & $22,3 \%$ & $14,0 \%$ & $63,0 \%$ \\
\hline Conceitue antígeno & $5,0 \%$ & $16,4 \%$ & $77,2 \%$ & $1,4 \%$ \\
\hline Conceitue anticorpo & $12,9 \%$ & $55,0 \%$ & $30,7 \%$ & $1,4 \%$ \\
\hline Conceitue vacina & $21,4 \%$ & $60,0 \%$ & $17,2 \%$ & $1,4 \%$ \\
\hline Conceitue imunidade humoral & $3,0 \%$ & $21,4 \%$ & $28,6 \%$ & $47,0 \%$ \\
\hline Conceitue imunidade celular & $3,0 \%$ & $27,1 \%$ & $27,1 \%$ & $42,8 \%$ \\
\hline
\end{tabular}




\begin{tabular}{|l|c|c|c|c|}
\hline Conceitue rejeição imunológica & $7,8 \%$ & $21,5 \%$ & $25,7 \%$ & $45,0 \%$ \\
\hline
\end{tabular}

Tabela 1 Classificação das respostas dadas a cada questão em adequadas, inadequadas, erradas e ausentes e suas respectivas porcentagens.

Verificamos que a maioria dos estudantes $(98,6 \%)$ relacionou a função do sistema imunológico apenas com a condição de defesa. Desse total, 52,0\% usaram palavras adequadamente relacionadas, atribuindo a função de proteção contra agentes infecciosos ou simplesmente de defesa do organismo. No entanto, um número significativo de estudantes $(46,6 \%)$ expressou essa mesma concepção usando termos inadequados como, por exemplo, corpo estranho como identificado na seguinte resposta - "Sistema imunológico é o responsável por combater os corpos estranhos que possam aparecer no organismo".

Quanto à classificação do sistema imunológico, apenas 12\% dos estudantes são capazes de fazer a distinção entre inato e adaptativo ou suas variações presentes nos livros como, natural e adquirido. Entre os demais, $3 \%$ apresentaram respostas inadequadas, $38,5 \%$ respostas erradas e $46,5 \%$ não responderam. Dentre as respostas consideradas inadequadas, frente às classificações internacionalmente aceitas, podemos citar: "Adaptativo e Passivo" e, entre as erradas, foi comum a classificação do sistema imunológico como "celular e humoral", conforme apresentado no exemplo - "De acordo com o caminho de ação pode ser classificado em humoral e celular".

Quando avaliamos a organização dos componentes do sistema imunológico identificamos que, dentre os 140 participantes deste trabalho, somente um estudante respondeu à questão adequadamente, deixando claro que existem os órgãos linfoides primários e secundários, as células linfoides, exemplificando-os e explicitando suas funções. Grande parte dos estudantes não respondeu esta questão (63\%). Entre a variedade de respostas consideradas inadequadas (22,3\%), a composição do sistema imunológico, formado quase que exclusivamente por células, em detrimento dos órgãos, predominou na representação dos estudantes, como por exemplo: "Os principais componentes do sistema imunológico são os macrófagos e linfócitos".

Entre as concepções de organização do sistema consideradas erradas (14\%) foi detectada confusão do conceito de sistema com o de resposta imunológica e de mecanismo de imunidade, como evidenciado respectivamente através das seguintes respostas: 1- "Estão organizados de forma que células de reconhecimento do antígeno cheguem primeiro, haja fagocitose e..." e 2"Imunoglobulinas realizam a 1a ação promovendo a identificação dos antígenos que então são atacados pelos leucócitos, células de defesa que se dividem em classes".

A concepção de antígeno de $77,2 \%$ dos estudantes foi considerada errada, $16,4 \%$ inadequadas e apenas $5 \%$ foram consideradas adequadas. Como exemplo de resposta considerada errada podemos citar - "agente externo capaz de provocar infecção", como exemplo R. B. E. C. T., vol. 6, núm. 1, Jan-Abr.2013 ISSN - 1982-873X 
de resposta inadequada - "qualquer corpo estranho que desencadeie uma resposta imunológica" e como exemplo de adequada - "qualquer substância capaz de ativar a resposta imunológica". Apenas $1,4 \%$ dos estudantes não responderam a esta questão.

Quanto à análise da concepção de anticorpo verificamos que $55,7 \%$ das respostas foram classificadas como inadequadas, $30,7 \%$ como erradas, $12,9 \%$ como adequadas e que $1,4 \%$ dos estudantes não responderam à questão. A maioria das respostas consideradas inadequadas atribui ao anticorpo a função de "destruir" o antígeno ("moléculas.. que tem a função de destruir e neutralizar os antígenos"). Verificamos, também, que 16,0\% dos estudantes confundem os níveis hierárquicos de composição dos seres vivos (moléculas / células). Estes pensam que o anticorpo é célula em vez de molécula como evidenciado pela seguinte resposta - "célula que se une ao antígeno para impedi-lo de causar danos".

Sobre a conceituação de vacina, apenas $21,4 \%$ dos estudantes a realizaram adequadamente, $17,2 \%$ de forma errada e $1,4 \%$ não responderam a esta questão. As respostas consideradas inadequadas, que corresponderam a $60 \%$, restringiram a função da vacina à produção de anticorpos. Conforme pode ser observado nas respostas a seguir, vacina é comumente confundida com: i- vacinação - "vacina é a injeção de antígenos "enfraquecidos" para que o organismo produza anticorpos; ii- método - "Vacina é o método pelo qual é inserida imunidade ativa, através de antígenos atenuados" e iii- imunidade - "Vacina é uma imunidade ativa, onde se "criam" anticorpos para determinada doença".

Quase a metade dos estudantes não respondeu às questões sobre imunidade celular $(42,8 \%)$ e imunidade humoral (47\%). Apenas $3 \%$ dos estudantes responderam adequadamente a cada uma destas classificações (humoral e celular). Quanto às respostas consideradas inadequadas, apenas $21,4 \%$ dos estudantes tinham a noção de que os anticorpos são os principais agentes na imunidade humoral e 27,1\% deles sabem que as células (linfócitos T e/ou macrófagos) estão envolvidas na imunidade celular. Entretanto, confundem o conceito de imunidade com, por exemplo, resposta imunológica - "conseguir produzir anticorpos contra ele rapidamente e eficientemente" ou "resposta produzida pelas células de defesa do organismo". Foram consideradas erradas $28,6 \%$ das respostas dadas para imunidade humoral (exemplo - "Resposta vinda de uma infecção prévia que ficou na memória") e 27,1\% das respostas dadas para imunidade celular (exemplo - "Reconhecimento de antígenos reincidentes").

Sobre memória imunológica, $42,8 \%$ das respostas foram consideradas inadequadas, posto que esse fenômeno foi relacionado apenas à imunidade humoral. Poucos estudantes $(10,7 \%)$ conceituaram adequadamente memória imunológica. As respostas erradas (40\%) revelaram que estes estudantes acreditam que a memória é ou se estabelece por: 1- anticorpos produzidos no primeiro contato com o antígeno, como se eles ficassem armazenados no organismo até que encontrem novamente com o mesmo antígeno, possibilitando, então, uma ação rápida ("são anticorpos produzidos em uma primeira infecção que reconhecem os antígenos em infecções 
posteriores") e 2- guardar a fórmula de responder a antígenos ("..a memória que guarda a "receita" para produção de anticorpos é a imunológica"). Não foi verificada qualquer relação com mudança na fisiologia celular muito menos do linfócito $\mathrm{T}$, responsável pela imunidade celular.

Quanto ao conceito de rejeição imunológica, $45 \%$ dos estudantes não responderam. Dentre os demais, apenas 7,8\% apresentaram conceitos adequados (exemplo - "Ataque do sistema imune a órgãos ou tecidos reconhecidos pelo sistema como estranhos"), $21,5 \%$ inadequados (exemplo - "Produção de anticorpos a algum tecido, o qual fora adicionado, a fim de substituir outro danificado.") e 25,7\% conceitos errados (exemplo - "Quando não há resposta imunológica"). Quando os estudantes foram capazes de associar a rejeição imunológica ao transplante de órgãos, porém sem a caracterização do fenômeno como consequência de resposta imunológica específica, o conceito também foi considerado inadequado. Por exemplo, "Rejeição do corpo contra algo como um órgão transplantado".

\section{Reflexão Crítica dos Resultados}

A partir da análise das respostas dos estudantes às questões do nosso questionário, constatamos que alguns conceitos são mais familiares para eles (antígeno, anticorpo, vacina e memória imunológica) do que outros (organização e classificação do sistema imunológico, rejeição imunológica). Esse resultado reflete os conteúdos presentes nos livros analisados visto que o estudo do sistema imunológico é pouco considerado nos livros texto do Ensino básico e a sua fisiologia está, equivocadamente, centrada na atividade dos anticorpos.

Os dados acima sugerem a forte influência das pesquisas realizadas entre as décadas de 20 e 50, do século passado, quanto ao estabelecimento da estrutura dos anticorpos e os fenômenos decorrentes de suas interações com moléculas de natureza diversa. Este período dominado pela abordagem química da Imunologia gerou os conhecimentos que foram amplamente empregados, e ainda são, no imunodiagnóstico, soroterapia e vacinação a favor da saúde pública (Gallanger, 1995).

A visão de sistema imunológico centrada apenas nos anticorpos mostra-se definitivamente equivocada, a partir do descobrimento dos linfócitos como célula central da resposta imunológica adaptativa (Gallanger, 1995; Miller, 1961). Inicia-se então a era da Imunologia moderna pautada pela formulação de perguntas de caráter mais biológico, cujas respostas promoveram uma verdadeira revolução paradigmática. Os novos métodos e as inúmeras pesquisas realizadas determinaram as bases fisiológicas do sistema imunológico. Isto quer dizer que avanço científico se faz, entre outras coisas, com pensamento baseado nas evidências e teorias (inclusive de outras áreas), novas tecnologias, e muito trabalho, é claro. É importante que o ensino de Imunologia seja pautado por abordagem crítica e reflexiva sobre o 
contexto histórico em que as principais descobertas aconteceram. Isso contribuiria para o aprendizado significativo, considerando a compreensão dos estudantes sobre a evolução dos conceitos científicos com vistas a conscientização para a reformulação conceitual.

Apesar de todo o conhecimento gerado nas últimas décadas do século $\mathrm{XX}$, a base microbiológica da origem da Imunologia é o senso comum e predomina na concepção dos estudantes participantes desse trabalho e dos autores dos livros analisados. Para a maioria deles o papel central da resposta imunológica é a defesa contra micro-organismos, sem haver qualquer consideração por sua participação na homeostasia.

A partir da primeira metade do século XX, com o advento das teorias sobre a complexidade na matemática (Viennot, 1979) e em seguida na fisiologia dos seres vivos, surgem novas teorias para a atividade do sistema imunológico (Abraham, 2002). Dentre estas está a noção de que o sistema imunológico, em associação com o nervoso e o endócrino, participa na manutenção da homeostasia do organismo. Surge a ideia de um sistema neuro-imuno-endócrino com a constatação do fato de que há o compartilhamento de moléculas e células entre eles (Coutinho, 2003; Ottaviani, 2011). Quanto maior o número de interações e redundâncias nos sistemas, maior sua complexidade. Se por um lado a complexidade dos sistemas biológicos é facilitadora da manutenção da homeostasia, por outro, os tornam mais difíceis de serem estudados, principalmente quando o ensino de ciências é praticado de forma linear.

A desconsideração pelos princípios necessários ao aprendizado significativo de conteúdo científico preconizadas por Ausubel (1983), a saber - a diferenciação progressiva (organização hierárquica conceitual) e a reconciliação integrativa (identificação de semelhanças e diferenças) entre ideias e conceitos - pode redundar em memorização de informações sem sentido para o estudante. A identificação da qualidade da organização conceitual sobre um assunto pode ser realizada através do mapa conceitual. Esse recurso foi desenvolvido por Novak (1984), com base no princípio da dependência entre o conhecimento novo a ser adquirido e o prévio, da teoria da aprendizagem significativa de Ausubel (1983). O mapa conceitual na concepção de seus autores é "um instrumento esquemático para representar um conjunto de significados incorporados em uma rede de proposições".

Resolvemos, então, construir um mapa conceitual a partir das concepções prévias dos estudantes participantes deste trabalho, para mais facilmente identificar: a parcialidade dos conhecimentos (falta de células e órgãos na composição do sistema), os principais problemas conceituais encontrados (antígeno, anticorpo, sistema-resposta-imunidade e memória imunológica), além do tipo de aprendizagem (mecânica) dos conceitos avaliados e discutidos. É possível observar no mapa que a maioria das proposições é equivocada. As proposições equivocadas estão representadas pelas relações entre as palavras em negrito dentro e fora das caixas sombreadas do mapa conceitual abaixo (figura 1 ). 


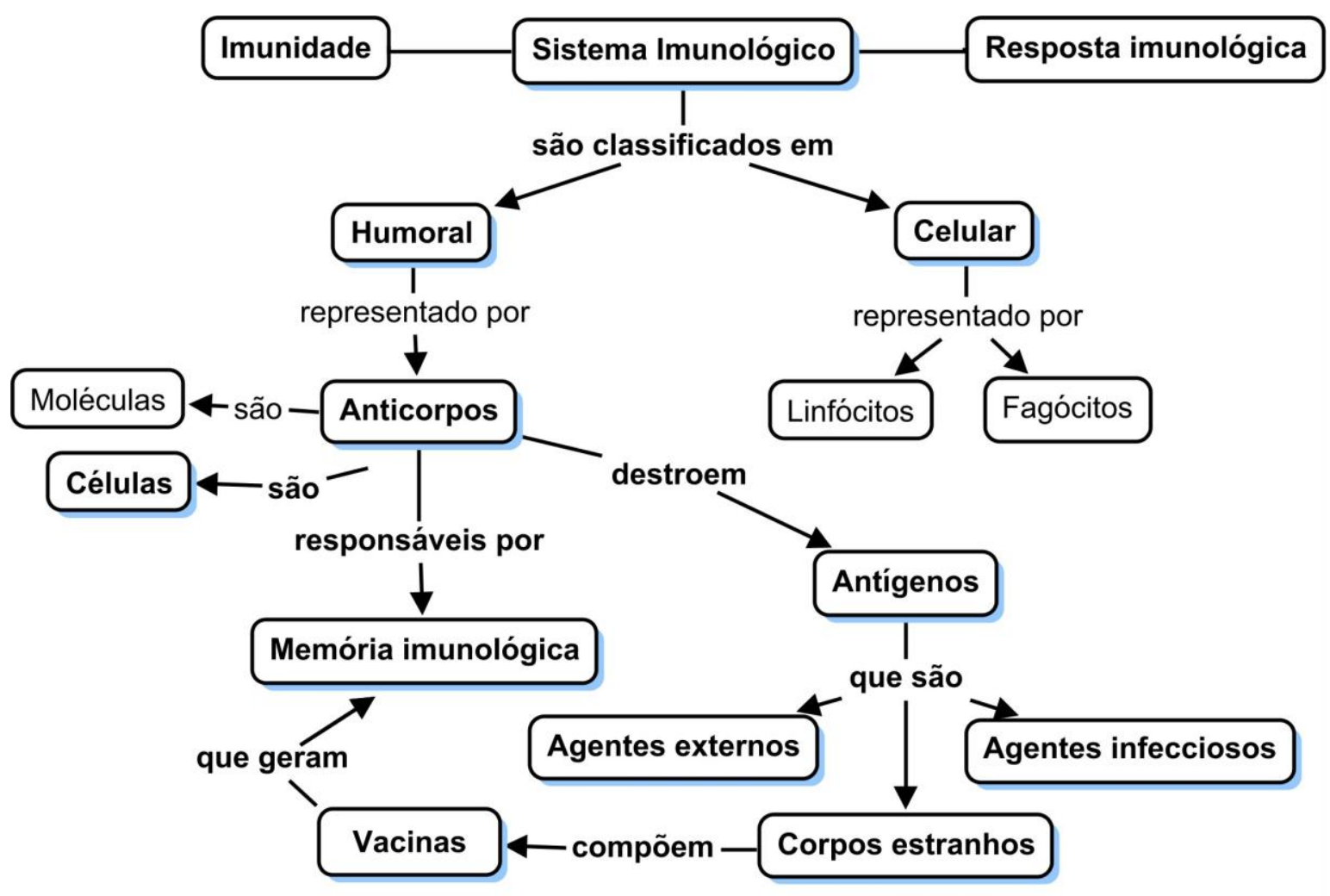

Figura 1 Mapa conceitual relativo à concepção inadequada da organização morfofuncional do sistema imunológico dos participantes da presente pesquisa antes de cursarem a disciplina Imunologia. Fonte: autor

Consideramos a aprendizagem mecânica, quando a informação é assimilada sem estabelecer uma relação reflexiva e consciente com conceitos existentes na estrutura cognitiva do indivíduo. Esse tipo de aprendizagem pode ser identificado através do conceito de memória imunológica e suas relações com vacina e anticorpo. Na concepção dos estudantes a memória imunológica é considerada como função dos anticorpos gerados no organismo a partir da vacina. Entretanto, se o tempo de vida média dos anticorpos não ultrapassa dias, após a resposta à vacina, como poderiam prevenir de uma doença infectocontagiosa muitos anos depois? Essa constatação da aprendizagem mecânica foi reforçada quando verificamos que nenhum estudante estabelece qualquer relação entre memória imunológica e mudança na fisiologia celular seja de linfócitos B ou T.

A falta de iniciação dos estudantes na formação de conceitos científicos pode ser revelada através do conceito de anticorpo que quando não é tautológico ("anticorpo é algo que reage com 
antígeno, que estimula a sua produção"), ele é teleológico ("produzido para destruir o antígeno diretamente") e equivocado. Segundo investigações realizadas por Vigostski (2008), "um conceito se forma mediante uma operação intelectual em que todas as funções mentais elementares participam de uma combinação específica". Portanto, é fundamental que os professores estimulem o desenvolvimento intelectual dos estudantes com atividades reflexivas para que possam conscientemente identificar os pseudoconceitos e construir conceitos verdadeiros.

Em nossa opinião, conceitos subsunçores formados inadequadamente podem prejudicar a compreensão de novos conhecimentos relacionados. Por exemplo, se para os estudantes, antígeno é considerado algo externo ao organismo (invasor ou corpo estranho) e que interage com anticorpo, isto pode dificultar a compreensão de que o sistema imunológico possa produzir anticorpos específicos para proteínas do seu próprio organismo, incluindo os próprios anticorpos.

A qualificação de antígenos como enfraquecidos ou fragilizados usada no conceito de vacina demonstra a associação restrita do conceito de antígeno com micro-organismos. A expressão da base microbiológica da Imunologia se manifesta mais uma vez.

Destacamos que a atualização dos conceitos imunológicos não é observada nos livros analisados no presente trabalho, assim como em outros. Através da avaliação da abordagem de vacina e vacinação realizada por Succi (2005), foi verificado algum tipo de impropriedade entre os 50 livros analisados. Dos 33 livros que continham informações sobre vacinas, 58\% eram incorretas, incluindo: erros na definição de vacina, erro no calendário vacinal, desatualização de conteúdo, omissão de conteúdo e ilustração inadequada.

Podemos citar alguns fatos recentes sobre vacinação que ilustram bem as consequências do desconhecimento do seu significado científico pela população. No Brasil, em 2008, indivíduos se submeteram a revacinação indevida para febre amarela, enquanto em 2010 membros de grupos de risco deixaram de se vacinar para o vírus H1N1 como relatado em jornais de grande circulação da época. Eis o paradoxo: os primeiros queriam garantir a saúde a qualquer custo enquanto os últimos acreditavam que adoeceriam se tomassem a vacina. Os cidadãos são, portanto, vítimas do desconhecimento e da incapacidade de pensar criticamente, fazendo escolhas equivocadas.

Outro resultado que revelou a distância entre o ensino de Imunologia e o cotidiano dos problemas de saúde da população foi a baixa frequência de conceitos científicos adequados relativos à rejeição imunológica e desta com transplante de órgãos. Este é um assunto cuja integração dos conceitos da Imunologia com os da Genética são fundamentais, por exemplo, para a compreensão pela população da necessidade de compor um imenso banco de doadores. Para tal, seria importante que além da institucionalização da interdisciplinaridade e da pesquisa no ensino de ciências, os docentes se apropriassem de métodos de ensino, que ativamente promovessem e evocassem a reflexão, o questionamento e a curiosidade dos estudantes. 
Identificamos vários conceitos inadequados nos livros do ensino básico que analisamos. Este fato gera a hipótese de que a escola básica através de seus livros com conteúdos desatualizados reforça as concepções inadequadas ao invés de promover as necessárias mudanças conceituais, isto é, do senso comum para o científico. Obviamente isso está contribuindo para que os egressos do Ensino Básico continuem com concepções inadequadas sobre o sistema imunológico. Esta é uma constatação preocupante considerando que o Ensino Médio é terminal para a grande maioria da nossa população. E quanto àqueles que seguem para o ensino superior, estão reconstruindo seus conceitos adequadamente? Ou seja, o ensino superior está contribuindo para a quebra ou manutenção do círculo vicioso ao formarem os bacharéis e professores?

A reposta para a pergunta acima pode ser negativa se predominar o ensino com foco no conteúdo em detrimento da formação científica crítica e reflexiva. Pois, ao consultarmos os livros texto, frequentemente adotados na universidade, verificamos que alguns conceitos também não são pertinentes. Por exemplo, alguns autores se referem ao antígeno como "corpo estranho" (Abbas, 2005) ou restringem a definição de antígeno a uma molécula que se liga especificamente ao anticorpo (Janeway, 2005), ignorando a sua interação com receptores de linfócitos T e B levando a ativação (positiva ou negativa) dessas células (Klein, 1990). Isso é preocupante, visto que os dois primeiros livros, usados no ensino superior, estariam servindo como fonte de reforço do senso comum ou de conceitos ultrapassados e equivocados.

Outro agravante na formação de professores é que não era comum o ensino de Imunologia nos currículos dos cursos de licenciatura em Ciências Biológicas de universidades públicas brasileiras, antes da última reforma do ensino superior, desencadeada pela lei de diretrizes e bases da educação nacional (Brasil, 1996). E mesmo quando a matéria Imunologia fazia parte do currículo do Curso, seja na condição de obrigatória ou optativa / eletiva, o conteúdo estava atrelado à microbiologia em uma única disciplina. Deste modo, é razoável inferir que os professores de biologia privados dos conhecimentos de Imunologia em sua formação estarão despreparados para o ensino da mesma, assim como para avaliar conteúdos ou produzi-los para os livros texto. Portanto, a aprendizagem permanente deveria fazer parte de todos os níveis de ensino no sistema público de educação.

Existe um grande número de trabalhos envolvendo concepções prévias em diferentes áreas da biologia como a genética e a biologia celular e molecular (Flores, 2003). Em um estudo sobre variações no entendimento de conceitos relacionados à genética, também foram identificados problemas conceituais entre alunos brasileiros de seis cursos de graduação (InfanteMalachias, 2010). Entretanto, no âmbito da Imunologia não temos conhecimento de estudo semelhante. 
Consideramos que os resultados apresentados são de extrema importância, visto que, no ensino superior é comum os docentes acreditarem que os conceitos avaliados no presente trabalho já foram aprendidos adequadamente pelos estudantes na sua formação básica. Entretanto, a baixa frequência de conceitos adequados expressados pelos participantes indica o contrário. Assim, o resultado no aprendizado pode não ser o esperado se o professor de Imunologia no ensino superior não observar em sua prática as concepções prévias dos estudantes e o uso estratégico de materiais de aprendizagem potencialmente significativos.

Autores como Novak (2002), vêm demonstrando a contribuição do uso do mapa conceitual para a mudança conceitual efetiva. Liu (2002) atribuiu a mudança conceitual dos estudantes em domínios ontológicos, epistemológicos e social/afetivo ao uso contínuo e colaborativo do mapa conceitual computadorizado.

De acordo com Vosnadiou (1994), as crianças precisam tomar consciência de suas teorias ingênuas e de que elas são passíveis de questionamento para que seja evitada a formação de equívocos conceituais. Essa conscientização pode ser alcançada ativamente pelo estudante através do portfólio, quando usado como um instrumento de reflexão e gerenciamento do aprendizado. No estudo de Buckley (2009), foram identificados os seguintes efeitos do uso do portfólio: melhoria no conhecimento e compreensão dos estudantes; uma maior autoconsciência e incentivo à reflexão e a capacidade de aprendizagem de forma independente.Existem experiências de êxito, principalmente no ensino de Física (Lino, 2011), com uso de materiais didáticos potencialmente significativos e intencionalmente empregados promovendo mudança conceitual e aprendizagem significativa.

É possível, portanto, que haja prejuízo para o aprendizado significativo de novos conhecimentos se o professor não considerar que aprendemos baseado no que já conhecemos (Ausubel, 2003) e não usar adequadamente e intencionalmente os recursos pedagógicos disponíveis.

Ao considerarmos, simplesmente, que o conceito representa a compreensão que temos sobre uma palavra, podemos dizer, através dos conceitos analisados, que os participantes desse trabalho manifestam um conhecimento equivocado sobre o sistema imunológico. Além disso, foi verificado que, de um modo geral, os participantes não tem noção do significado de conceito. Suas concepções, se lidas isoladamente, impedem a identificação das palavras as quais referemse, tal é a imprecisão, ausência de características e propriedades fundamentais, que permitiriam distingui-las de uma centena de outras palavras - por exemplo, apresentar agente externo como conceito de antígeno.

O conjunto dos resultados revela a falta de domínio da linguagem e da linguagem imunológica atual entre os universitários participantes desse trabalho. Segundo Moreira (2003), "aprender uma ciência é aprender uma nova linguagem" e isso inclui o uso das palavras com seus 
significados, que por sua vez é imprescindível na aprendizagem significativa do conteúdo. A linguagem científica deverá ser atualizada e ter o mesmo significado para ambas as partes (estudante e professor) para que o diálogo e consequentemente o aprendizado sejam efetivos.

Verificamos, que em plena era da complexidade, da inter e multidisciplinaridade, a maioria dos estudantes, participantes desta pesquisa, ainda manifesta o senso comum sobre a função do sistema imunológico, vacina, antígeno e anticorpo, assim como desconhecem os órgãos que compõem o sistema imunológico, que é confundido com resposta imunológica ou imunidade.

Considerando que o sistema imunológico é parte do corpo humano e contribui para a homeostasia do organismo, o ensino básico não deveria negligenciá-lo. Caberá aos profissionais da educação reverter esse quadro, particularmente o biólogo, que é responsável pelo ensino de ciências e de biologia na formação básica da população. Entretanto, para que o sistema imunológico seja apresentado como uma entidade integrada aos demais sistemas do organismo é necessário que a formação dos professores os capacite a uma educação científica significativa crítica, parafraseando Marco A. Moreira (2000). Do contrário, pode haver predominância de aprendizado de conteúdos de maneira não científica, literal e arbitrária, sem proporcionar as mudanças conceituais necessárias à formação para a vida em sociedade.

\section{Considerações finais}

A maioria dos estudantes que participou deste trabalho finalizou o ensino médio sem conhecimentos básicos relacionados à Imunologia e com pseudoconceitos que permitem a comunicação, mas podem interferir na compreensão de novos conhecimentos.

É importante, portanto, que os resultados desse trabalho sejam intencionalmente associados ao uso estratégico de recursos que promovam ativa e significativamente a reconstrução conceitual, proporcionando generalização dos conceitos científicos em contextos não formais de ensino.

Seria importante, também, que se adotasse no processo formativo a perspectiva da aprendizagem significativa e crítica, sociocultural e ativa em cursos de formação de professores, bacharéis e pós-graduação, visto que, mudar convicções e atualizar conceitos científicos, na perspectiva do pensamento científico e reflexivo, dependerá também da competência pedagógica do professor.

\section{Referências}

Abbas, A.; Lichtman, A. e J. Pober. Imunologia Celular e Molecular. 5 ed. Rio de Janeiro: Revinter. 2005.

R. B. E. C. T., vol. 6, núm. 1, Jan-Abr.2013 ISSN - 1982-873X 
Abraham, R. H. The Genesis of Complexity. Em: http://www.ralphabraham.org/ 2002.

Ader, R. e N. Cohen. Behaviorally conditioned immunosuppression. Psychosomatic Medicine, v 37, n 4, 1975.

Ausubel, D. P.; Novak, J. D. e H. Hanesian. Psicologia educacional. Rio de Janeiro: Interamericana. 1980.

Ausubel, D. P. Aquisição e Retenção de Conhecimentos: Uma Perspectiva Cognitiva. Lisboa: Plátano Edições Técnicas. 2003.

Brasil. Lei de Diretrizes e Bases da Educação Nacional. Em http://portal.mec.gov.br/arquivos 1996.

The educational effects of portfolios on undergraduate student learning: A Best Evidence Medical Education (BEME) systematic review. Medical Teacher, v 31, n 4, 2009.

Coutinho, A. A walk with Francisco Varela from first- to second-generation networks: In Search of the Structure, Dynamics and Metadynamics of an Organism-centered Immune system. Biological Research, v 36, n 1, 2003.

DiCarlo, S. E. Cell biology should be taught as science is practiced. Nature Reviews Molecular Cell Biology, v 7, 2006.

DiCarlo, S. E. Too much content, not enough thinking, and too little fun. Advanced Phisiology Education, v 33, 2009.

Driver, R. Psicologia Cognoscitiva y Esquemas Conceptuales de los Alumnos. Enseñansa de las Ciências, v 4, n 1, 1986.

Driver, R. Un Enfoque Constructivista para el Desenrrollo del Currículo em Ciências. Enseñansa de las Ciências, v 6, n 2, 1988.

Flores, F., Tovar, M. E. e L. Gallegos. Representation of the cell and its processes in high school students: An integrated view. International Journal of Science Education, v 25, n 2, 2003.

Gallanger, R. B.; Gilder, J.; Nossal, G.J.V. e Salvatore, G. Immunology: The making of a modern science. London: Academic Press. 1995.

Houaiss, A. e Villar, M.S. Dicionário Houaiss da língua portuguesa. Rio de Janeiro: Objetiva. 2001. Humprhey, J. H. e R. G. White. Immunology for students of Medicine. Oxford and Edinburg: Blackwell. 1970.

Infante-Malachias, M.E., Padilha, I.Q.M, Weller, M. e Santos,S. Comprehention of basic genetic concepts by brazilianundergratuate students. Revista Eletrónica de Enseñanza de las Ciências, v 9, n 3, 2010. 
Janeway, Jr. et al. Imunologia - O sistema imune na saúde e na doença. Porto Alegre: Artmed Bookman. 2005.

Klein, J. Immunology. Berlin: Blackwell. 1990.

Lewis, J. e U. Kattmann. Traits, genes, particles and information: re-visiting students' understandings of genetics. International Journal of Science Education, v 26, n 2, 2004.

Lino, A. e Fusinato, P. A. A influência do conhecimento prévio no ensino de Física Moderna e Contemporânea: um relato de mudança conceitual como processo de aprendizagem significativa.

Revista Brasileira de Ensino de Ciência e Tecnologia, v 4, n 3, 2011.

Liu, X. Using Concept Mapping for Assessing and Promoting Relational Conceptual Changein Science. Science \&Education, v 88, 2004.

Matos, S. A.; Coutinho, F. A.; Chaves, A. C. L.; Costa, F. J. \& Amaral, F. C. Referenciais teóricometodológicos para a análise da relação texto-imagem do livro didático de Biologia. Um estudo sobre o tema embriologia. Revista Brasileira de Ensino de Ciência e Tecnologia, v 3, n 1, 2010.

Miller, J. F. A. P. Immunological function of the thymus. Lancet, 2, 1961.

Moreira, M.A. Linguagem e Aprendizagem significativa. In II Encontro Internacional Linguagem, Cultura e Cognição. Belo Horizonte, 2003.

$\begin{array}{lllll}\text { Moreira, } & \text { M. A. Aprendizagem } & \text { significativa } & \text { crítica. }\end{array}$ http://www.if.ufrgs.br/ moreira/apsigcritport.pdf, 2010.

Mortimer, E. e P. Scott. Atividade Discursiva em Sala de Aula de Ciências: Uma Ferramenta Sociocultural para Analisar e Planejar o Ensino. Enseñansa de las Ciências, v 7, 2002.

Mortimer, E. F. "Conceptual change or conceptual profile change?". Science \& Education, v 4, n 3, 1995.

Novak, J. D. e Gowin, D. B. Learnig how to learning. New York: Cambridge University Press, 1984.

Novak, J.D. Meaningful Learning: The Essential Factor for Conceptual Change in Limited or Inappropriate Propositional Hierarchies Leading to Empowerment of Learners. Science \& Education, v 86, 2002.

Ottaviani, E.Evolution of immune-neuroendocrine integration from an ecological immunology perspective. Cell Tissue Res, v 344, 2011.

Pedrancini, V.A.; Corazza, M.J. e M.T.B. Galuch. Mediação Pedagógica e a formação de conceitos científicos sobre hereditariedade. Revista Eletrónica de Enseñanza de las Ciências, v10, n1, 2011. 
Succi, C.M.; Wickbold, D. e R.C.M. Succi. A vacinação no conteúdo de livros escolares. Revista Brasileira de Educação Médica, v 51, n2, 2005.

Viennot, L. Spontaneous Reasoning in Elementary Dynamics. European Journal of Science Education, v1, n2, 1979.

Vigotski, L.S. Pensamento e Linguagem. São Paulo: Martins Fontes. 2008.

Vosnadiou, S. Capturing and modeling the process of conceptual change.Learning and Instruction, v. 4, 1994.

Quinn, L.y. Immunological concepts. lowa: State. 1968.

Claudia Marcia Borges Barreto. Universidade Federal Fluminense. Professora Adjunta do Departamento de Imunobiologia. Doutora em Patologia - Universidade Federal Fluminense. Coordenadora do PIBID-Biologia UFF desde 2011. claudiamarcia08@gmail.com

Gerlinde Agate Platais Brasil Teixeira. Universidade Federal Fluminense. Professora Adjunta do Departamento de Imunobiologia. Doutora em Patologia - Universidade Federal Fluminense. Professora permanente dos programas de: Pós-graduação em Patologia UFF e Pós-graduação em Ciencias e Biotecnologia - UFF. Coordenadora do PIBID-Biologia UFF desde 2009.

gerlinde.teixeira@gmail.com 